\title{
Gorlin-Goltz Syndrome-Case Report and Review
}

\author{
Parveen A1, Tahir A 2*, Shujahhussain $^{3}$ and Javaidahmadwani4 \\ ${ }^{1}$ Professor and Head, Oral and maxillofacial surgery, Indira Gandhi government \\ dental College Jammu, India \\ ${ }^{2}$ Junior resident, oral and maxillofacial surgery, Indira Gandhi government dental \\ College Jammu, India \\ ${ }^{3}$ Senior resident, Indira Gandhi government dental College Jammu, India \\ ${ }^{4}$ Dental surgeon, jammu and Kashmir, India
}

*Corresponding author: Tahir Ahmad, Junior resident, oral and maxillofacial surgery, Indira Gandhi government dental College Jammu, India, E-mail: t.a.tahir66@gmail.com

\begin{abstract}
The Gorlin-Goltz syndrome (GGS) or (the nevoid basal cell carcinoma syndrome-NBCCS) is a rare autosomal dominant and multiple organ syndrome. The common manifestations include multiple odontogenic keratocysts in the jaws, multiple basal cell nevi on the skin with an early age onset, palmar pits,bifid or splayed ribs, high arched palate, euryopia , areas of hyper-pigmentation in the upper eyelid of left eye, dorsal surface of hands, calcified diaphragm sellae, calcifications of the falx cerebri. Although all the manifestations may not be present in all the patients. In this case report we report only case of gorlin-goltz syndrome in jammu region in young 20 year old female patient and are reviewing the features of the Gorlin-Goltz syndrome.
\end{abstract}

Keywords: Gorlingoltz; Basal cell; Bifidribs; Okc; Autosomal

\section{Introduction}

GGS, also known as nevoid basal cell carcinoma syndrome (NBCCS), is an infrequent multi systemic disease with an autosomal dominant trait, with a complete penetrance and variable expressivity, though sporadic cases have been described [1,2]. GGS shows a predisposition to neoplasms and other developmental abnormalities. The estimated prevalence varies from $1 / 57,000$ to $1 / 256,000$ among various studies, with a male-to-female ratio of 1:1 [2]. The first report of the syndrome was made in 1894 by Jarisch and White in a patient with multiple basal cell carcinomas, scoliosis, and learning disability. Binkley and Johnson in 1951, and Howell and Caro in 1959 suggested a relationship between basal cell epitheliomas and developmental malformations. It was delineated only in 1960 by Robert James Gorlin and William Goltz $[3,4]$ who established the classical triad (multiple basocellular epitheliomas, keratocysts in the jaws and bifid ribs) that characterizes the diagnosis of this syndrome. This triad was later modified by Rayner et al. who established that the diagnostic criteria would require cysts to appear in 


\section{Medical Journal of Clinical Trials \& Case Studies}

combination with calcification of the falxcerebri or palmar and plantar pits [5-7].

It is an autosomal dominant disorder with a genetic locus on chromosome sub bands and bands 9q22.3-q31, as determined with linkage analysis [8]. It is also called as the fifth phakomatosis due to the presence of multiple cutaneous, skeletal, ophthalmic and neurological abnormalities. It comprises of skeletal features such as the bifid rib, frontal and parietal bossing and mandibular prognathism and cutaneous abnormalities such as multiple basal cell carcinomas and palmar and plantar keratosis. NBCCS can also include concomitant hypertelorism, mental retardation, strabismus, calcification of the falxcerebri and medulloblastomas [9].

In addition to the classical triad described by Gorlin and Goltz, calcification of the falxcerebri, palmar and plantar epidermal pits, spine and rib anomalies, relative macrocephaly, facial milia, frontal bossing, ocular malformation, medulloblastomas, cleft lip and/or palate, and developmental malformations have also been established as features of the syndrome [5-7]. The pathogenesis of GGS is attributed to be the consequence of abnormalities in the PTCH gene. The loss of human patched gene (PTCH1 gene), a tumor suppressor gene, forms the molecular basis of the syndrome [10]. This gene is significant for embryonic structuring and cellular cycle, thus its mutation leads to the development of the disease including neoplasms. The syndrome exhibits abnormalities similar to those seen in people exposed for long periods to UV radiation. Several different mutations of the PTCH1 gene have also been identified in patients with GGS [2,3].

\section{Case Report}

A 20 YEAR OLD female reported to our OPD of oral and maxillofacial surgery with complaint of intraoral discharge in the lower left tooth back region since 2 months. Patient was apparently alright 2 months back after she experienced swelling in the Mandibular posterior region which was followed by intermittent slowly progressing pain, aggravating on eating and relieved on medication. This was also followed by discharge of fluid from the same region.

On general examination, patient was conscious cooperative and well oriented with person place and time. Extra oral examination revealed frontal bossing, presence of multiple nevi, palmar pits in both hands, prominent supra orbital ridges (Figures $1 \& 2$ ).

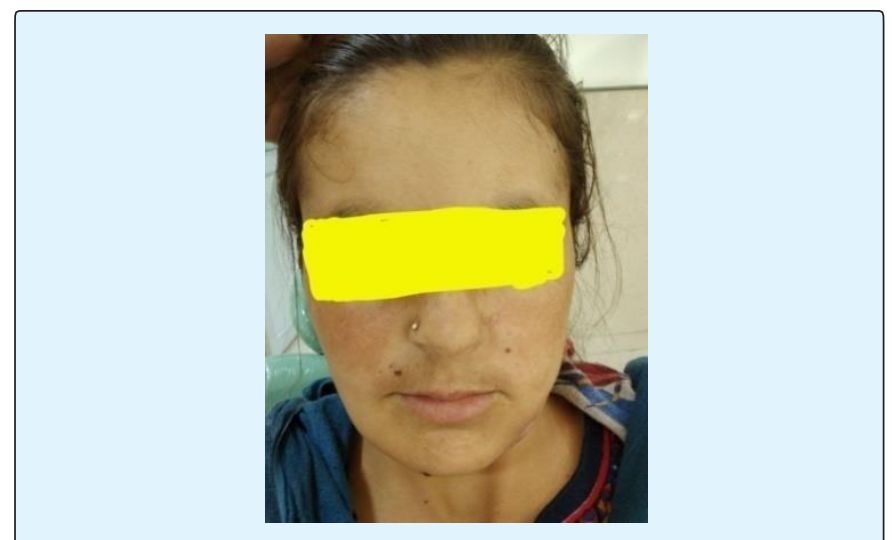

Figure 1: Frontal bossing and multiple oral nevi.

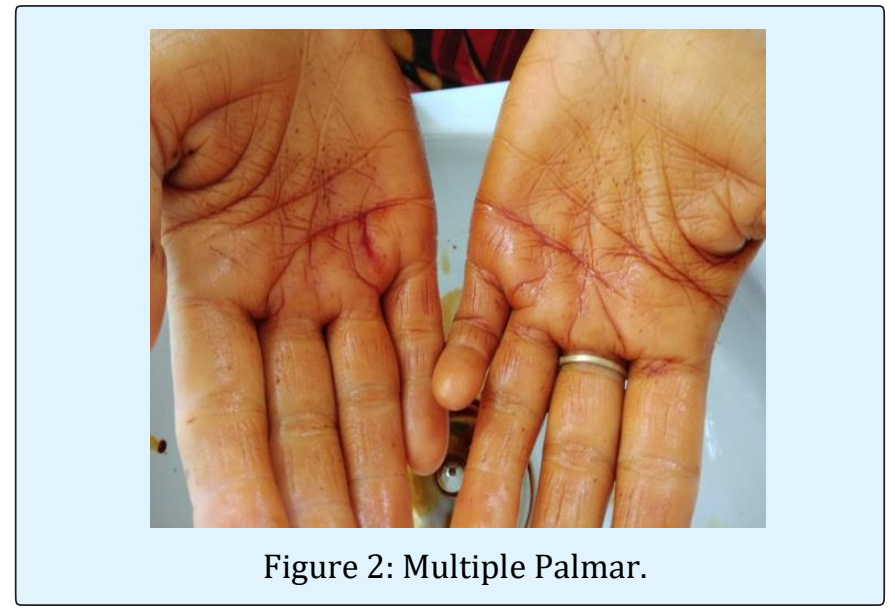

An Intra oral examination revealed carious 36, vestibular tenderness wrt 363738 and on application of pressure with finger, white discharge of fluid was seen in this region.

An Orthopantomogram (OPG) of the patient showed multiple cysts in both maxilla and mandible Figure 3.

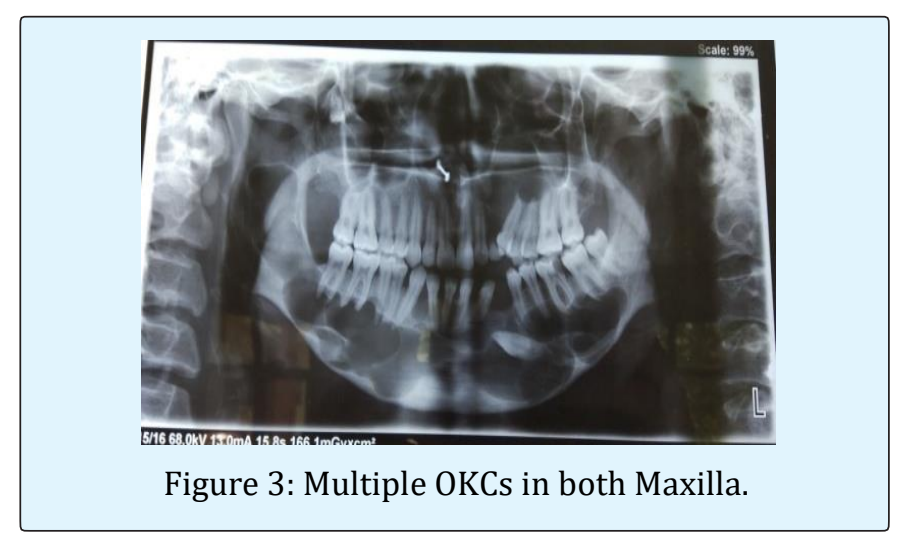




\section{Medical Journal of Clinical Trials \& Case Studies}

An impacted left Mandibular canine was seen with loss of the cortex in the Mandibular body region on the left extending till the ramus on the right side, involving neck of the condyle. In maxilla Large radiolucent lesion was seen in the periapical region extending with respect to the right second molar till canine area and another one was seen in the left posterior part of the maxilla, extending along the periapical region of left premolar to left second molar. The lesions also involved the mandibular canal on both sides. Surgical enucleation of all the cysts was started, followed by curettage Figure 4 .

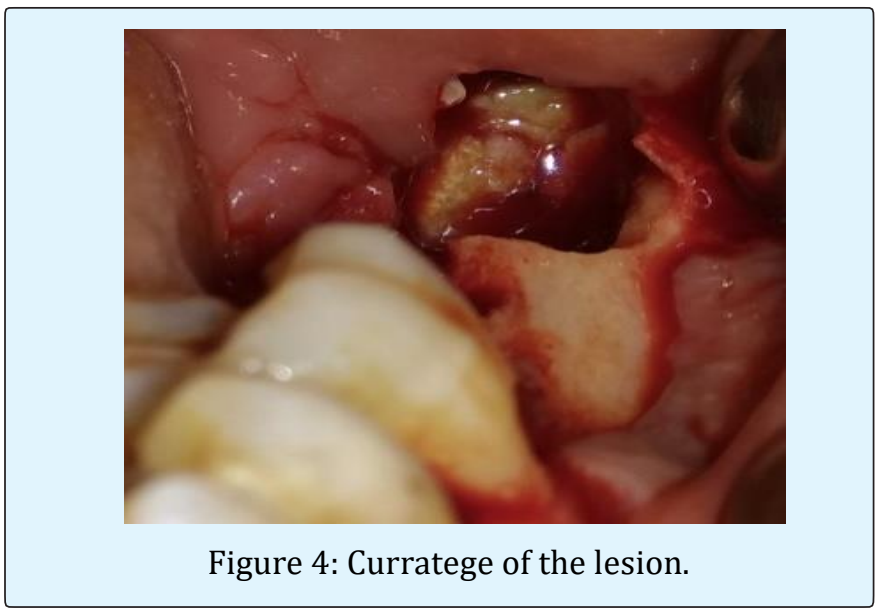

Chest radiograph of the patient showed markedly splayed ribs on the right side Figure 5 which further substiatiated the gorlin goltiz syndrome Figure 5 .

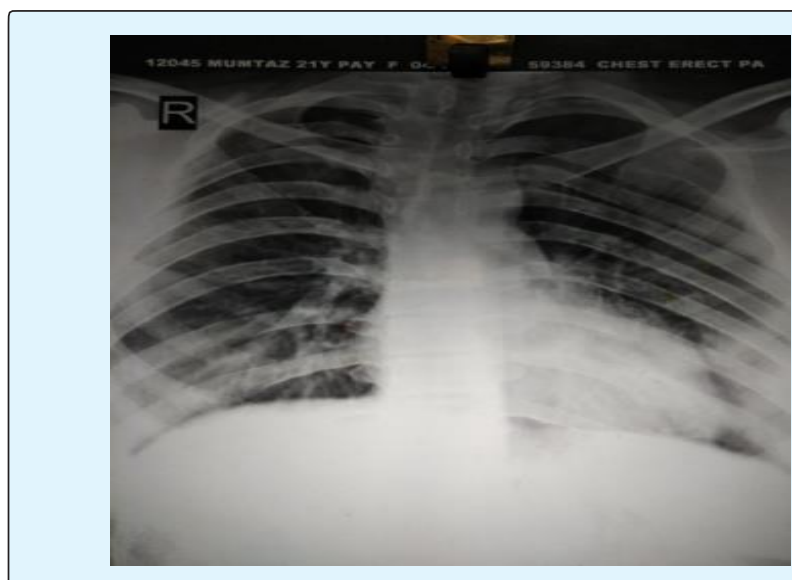

Figure 5: Splayed ribs on right side.

The specimen were sent for histopathological examination which revealed a typical odontogenic keratocyst made up of thin layer of parakeratized epithelium separated from the underlying connective tissue Figure 6.

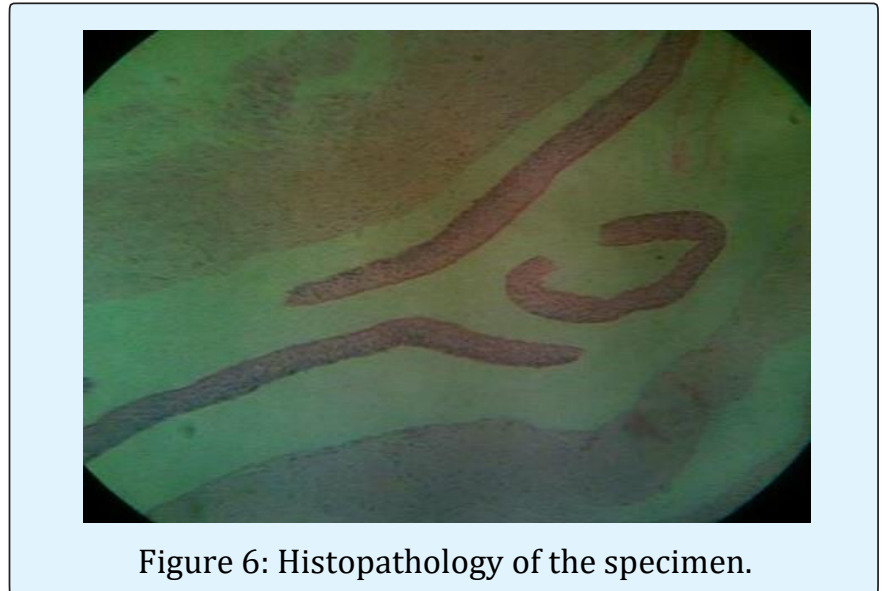

Further skin lesions in the form of basal cell nevus, palmer or plantar pits or keratosis were present. Thus based on all clinical radiographical and histopathological evidence, aproviosonal diagnosis of Gorlin Goltiz syndrome was made.

\section{Discussions}

Gorlin-Goltz syndrome also known as Nevoid Basal Cell Carcinoma Syndrome was described for the first time in 1894 by Jarisch and White. The disease is an autosomal dominant disorder mainly characterized by the presence of multiple basal cell carcinomas, odontogenic keratocysts of the jaw and palmarpits [11,12]. The estimated prevalence varies from $1 / 57000$ to $1 / 256000$ [13]. It is seen in males and females equally [14]. This syndrome is due to tumor suppressor gene mutation in the long arm of chromosome 9 (q22.3-q31). Approximately, 35-50\% of cases are due to new mutations [15]. Evans et al. first established major and minor criteria for diagnosis of this rare entity, later modified by Kimonis et al. [16,17]. Although these criteria are not absolute, they can help guiding the clinician's laboratory evaluation for both diagnostic purposes and routine follow up.

\section{Major criteria consist of}

1. More than two basal cell carcinomas or one in patient less than 20 years old

2. Odontogenic keratocysts of the jaw

3. Three or more palmar or plantar pits

4. Bilamellar calcifications of falxcerebri and tentorium

5. Bifid or fused, or markedly splayed ribs

6. First-degree relative with Gorlin-Goltz syndrome. 


\section{Medical Journal of Clinical Trials \& Case Studies}

\section{Minor criteria consist of}

a. Macrocephaly,

b. Congenital anomalies (cleft lip or palate, frontal bossing, coarse facies, and moderate or severe hypertelorism)

c. Other skeletal anomalies (Sprengel deformity, marked pectus deformity, and marked syndactyly of the digits)

d. Radiologic anomalies (such as bridging of the sellaturcica, vertebral anomalies, modelling defects of the hands and feet, or flame-shaped lucencies of the hands and the feet) 9 Ovarian fibromaor myeloblastoma. 2 major criteria or 1 major and 2 minor criteria are obligatory in order to diagnose GorlinGoltzsyndrome [18].

Our patient had three major features of NBCCS, namely, multiple odontogenic keratocysts in the jaw,multiple palmarpits, splayed ribs on the right side and minor features such as the frontal bossing, prominent supraorbital ridges thus suggesting it to be a case of the Gorlin-Goltz syndrome.

Regarding the site predilection, OKCs which are associated with NBCCS are more common in the mandible with $69 \%$ involvement, as compared to $31 \%$ in the maxilla. In the mandible, $43 \%$ OKCs occurs in the molar ramus region, followed by $18 \%$ in the incisor- $\neg$ canine area. In the maxilla, 14\% OKCs were found to occur in the incisor- $\neg$ canine area, followed by molar tuberosity with $12 \%, 7 \%$ in the mandibular premolar region and $3 \%$ in the maxillary premolar region. Regarding the male to female ratio, it was 1:0.62 for OKCs which were not associated with NBCCS and 1:1.22 for OKCs in NBCCS. This shows that simple keratocysts are more common in males, but that more females seem to have NBCCS [19].

Based on histopathological studies, parakeratinizaᄀtion, intramural epithelial remnants and satellite cysts were found to be more frequent among the OKCs which were associated with NBCCS than in the solitary keratocysts [20].

In our patient, the lining of the OKCs revealed the presence of parakeratinization and epithelial remnants in the connective tissue wall, thus indi-cating the association with NBCCS. Daughter cysts were also seen by histopathology in our patient. The term "multiple cysts" does not necessarily mean that the patient must have more than one cyst at a given time; rather it refers to the occurrence of cysts over the life time of the patient [21]

Tahir A, et al. Gorlin-Goltz Syndrome-Case Report and Review. Med J Clin Trials Case Stud 2017, 1(2): 000110.
There is no specific laboratory test to diagnose NBCCS, although the affected patients may have high levels of cyclic adenosine monophosphate and impaired phosphate diuresis on parathormone challenge [22]. The treatment of the GorlinGoltz syndrome is in accordance with the generally accepted rules for the treatment of basal cell carcinomas and keratocysts in other patients. Radiation should be avoided, as it may trigger off the development of other tumors in the adjacent skin areas. Cystectomy, including the removal of the bony walls of the resulting cavity, is an adequate surgical treatment for the odontogenickeratocysts. In the treatment of the recurrent OKCs which are associated with NBCCS, the overlying surface epithelium should be excised along with the cystic lining to prevent recurrences from the residual epithelial islands and microcysts [23].

In addition, the use of Carnoy's solution following cyst enucleation (applied only over the areas where the cyst is attached to the mucosa) and cryosurgery (because of the unique ability of liquid nitrogen to devitalize the bone in situ while leaving the inorganic framework untouched) is advocated to kill the epithelial remnants and the dental lamina within the osseous structures and to thus, prevent recurrences [24].

\section{Conclusion}

This rare case highlights the importance of proper evaluation and need of clinical and radio graphical evidence in establishing diagnosis in rare syndromes. In addition to this, proper treatment modalities and counseling in these patients along with regular follow up increases the chances of survival in such rare syndromes. It's also highly recommended to report such cases along with genetic counseling in family members of such patients to improve their survival.

\section{References}

1. Casaroto AR, Rocha Loures DCN, Moreschi E, Vanessa C Veltrini, Cleverson L Trento, et al. (2011) Early diagnosis of Gorlin-Goltz syndrome: case report. Head and Face Medicine 7(2).

2. Yordanova I, Gospodinov D, Kirov V, Pavlova V, Radoslavova G (2007) A familial case of gorlin-goltz syndrome. Journal of IMAB 13(1): 59-63.

3. Ljubenovi M, Ljubenovi D, Bini I, Jovanovi D, Stanojevi M (2007) Gorlin-Goltz syndrome. Acta Dermatoven APA 16(4): 166-169. 


\section{Medical Journal of Clinical Trials \& Case Studies}

4. de Amezaga AOG, Arregui OG, Nuno SZ, Sagredo AA, Urizar JMA (2008) Gorlin-Goltz syndrome: clinicopathologic aspects. Med Oral Patol Oral Cir Bucal 13(6): E338-E343.

5. L Lo Muzio (2008) Nevoid basal cell carcinoma syndrome (Gorlin syndrome). Orphanet Journal of Rare Diseases 3: 32.

6. Kimonis VE, Goldstein AM, Pastakia B, Yang ML, Kase $\mathrm{R}$, et al. (1997) Clinical manifestations in 105 persons with nevoid basal cell carcinoma syndrome. Am J Med Genet 69(3): 299-308.

7. Santana N, Yashodha Devi BK, Jatti D (2011) GorlinGoltz syndrome-a case report. Journal of the Indian Dental Association 5(4): 521.

8. Gailani MR, Bale SJ, Leffell DJ, Di Giovanna JJ, Peck GL et al. (1992) Developmental defects in Gorlin syndrome related to a putative tumor suppressor gene on chromosome. Cell 69(1): 111-117.

9. Lindeboom JA, Kroon FH, de Vires J, van den Akker HP (2003) Multiplerecurrent and de novo odontogenic keratocysts associated with oral-facial-digital syndrome. Oral Surg Oral Med Oral Pathol Oral Radiol Endod 95(4): 458-462.

10. C Kalogeropoulou, $P$ Zampakis, $S$ Kazantzi, $P$ Kraniotis, NS Mastronikolis (2009) Gorlin-Goltz syndrome: incidental finding on routine ct scan following car accident. Cases Journal 2: 9087.

11. Kolm I, Puig S, Iranzo P, Malvehy J (2006) Dermoscopy in Gorlin-Goltz syndrome. Dermatol Surg 32(6): 847-851.

12. Rozylo-Kalinowska I, Rozylo TK (2002) Odontogenic keratocyst in Gorlin-Goltz syndrome. Ann Univ Mariae Curie Sklodowska 57(2): 79-85.

13. Lo ML (2008) Nevoid basal cell carcinoma syndrome (Gorlin syndrome). Orphanet J Rare Dis 3: 32.

14. Kimonis VE, Goldstein AM, Pastakia B, Yang ML, Kase $\mathrm{R}$ et al. (1997) Clinical manifestations in 105 persons with nevoid basal cell carcinoma syndrome. Am J Med Genet 69(3): 299-308.
15. Kalogeropoulou C, Zampakis P, Kazantzi S, Kraniotis P, Mastronikolis NS (2009) Gorlin-Goltz syndrome: Incidental finding on routine CT scan following car accident. Cases J 2: 9087.

16. Evans DG, Ladusans EJ, Rimmer S, Burnell LD, Thakker $\mathrm{N}$ et al. (1993) Complications of the nevoid basal cell carcinoma syndrome: results of a population based study. J Med Genet 30(6): 460-464.

17. Kimonis VE, Mehta SG, Digiovanna JJ, Bale SJ, Pastakia B (2004) Radiological features in 82 patients with nevoid basal cell carcinoma (NBCC or Gorlin) syndrome. Genet Med 6(6): 495-502.

18. Manfredi M, Vescovi P, Bonanini M, Porter S (2004) Nevoid basal cell carcinoma syndrome: A review of the literature. Int J Oral Maxillofac Surg 33(2): 117124.

19. Karthiga S Kannan, Sivapatha B Sundharam, R Manikandan (2006) Nevoid basal cell carcinoma syndrome. IJDR 17(1): 50-53.

20. Dominguez FV, Keszler A (1988) Comparative study of keratocysts, associated and non-associated with nevoid basal cell carcinoma syndrome. J Oral Pathol 17(1): 39-42.

21. Woolgar JA, Rippin JW, Browne RM (1987) The odontogenic keratocyst and its occurrence in the nevoid basal cell carcinoma syndrome. Oral Surg Oral Med Oral Pathol 64(6): 727-730.

22. Bakaeen G, Rajab LD, Sawair FA, Hamdan MA, Dallal ND (2004) Nevoid basal cell carcinoma syndrome: a review of the literature and a report of a case. Int J Paediatr Dent 14(4): 279-287.

23. Myoung $\mathrm{H}$, Hong SP, Hong SD, Lee JI, Lim CY et al. (2001) Odontogenic keratocyst: review of 256 cases for recurrence and clinico $\neg$ pathologic parameters. Oral Surg Oral Med Oral Pathol Oral Radiol Endod 91(3): 328-333.

24. Stoelinga PJ (2003) Excision of the overlying, attached mucosa, in conjunction with cyst enucleation and treatment of the bony defect with carnoy solution. Oral Maxillofac Surg Clin N Am 15(3): 407414. 